already American tapes for the medical and related literature (MEDLARS) and for certain fields in chemistry (American Chemical Society services) are being evaluated and exploited. The literature of the nuclear sciences is likely to be the next on the list of such international exchange.

The ultimate efficiency and success of these pioneering projects depends partly on 'hardware' (the unit costs are falling) but much more importantly on minimum standards of input format and compatibility, and on considerable improvements in indexing and classification techniques. It is this sort of 'software' rather than 'hardware' that is the limiting factor at present. Subject control becomes increasingly frustrated by linguistic variability and semantic ambiguity as the coverage is widened and the number of entries becomes large. In other words large stores of indexed references duplicated on magnetic tapes and widely distributed, demand very high standards of indexing if searching is to be efficient. To achieve this, men and women of training, discretion and real ability are needed.

\title{
Abstracts and reviews as means of conveying information
}

\section{By E. J. ManN, Commonwealth Bureau of Dairy Science and Technology, Shinfield, Reading}

It has been estimated that some 50000 technical and scientific periodicals are published in the world today and that the number is growing rapidly, with a corresponding rise in the output of scientific and technical papers. In the chemical field alone, it has been calculated that the output of papers is doubling every 8 years and it is a generally accepted fact today that it is outside the competence of any scientist, however narrow his field of interest may be, to keep up to date by scanning all the requisite primary literature in his field. That is why abstract and review journals were created. Abstracting corresponds to the milk drying process. A good abstract, like a good milk powder, retains the essential ingredients of the original product in a highly concentrated form, the non-essential ingredients having been eliminated.

Abstract journals serve two primary functions: (I) to alert readers to the latest developments in their particular field; (2) to provide a cumulative information store for retrospective searching. To serve these functions effectively, abstract journals should cover the literature of their field completely, should be published as frequently as practicable, with the minimum of delay between publication of the original article and that of its abstract, and should be provided with comprehensive and up-to-date author and subject indexes. If abstract journals today are sometimes referred to as 'old-fashioned' media of communication, it is largely due to the fact that, through lack of sufficient funds or for some other reason, they have failed to satisfy one or more of these requirements.

Unfortunately, the 'primary' literature explosion has been followed by a 'secondary' literature explosion, a recent publication listing some 1800 abstracting services 
in the field of science and technology. A high proportion of the scientific and technological papers published today are abstracted three or four times over by different organizations, and readers are probably as overwhelmed by the multiplicity of abstracts and abstracting services as they are by the explosive growth of the primary literature.

It is likely, however, that the advent of the computer in the field of information storage and dissemination, far from destroying the value of abstracts, will give them a new and extended lease of life. Publishing an abstract journal via a computer not only enables the most modern and speediest printing techniques to be employed; it also makes possible the generation of computer-aided indexes and, most important of all, provides an additional computer store of the information published in the abstract journal. From this computer store, abstracts on related subjects, suitably tagged with relevant keywords, can be retrieved and printed out for specific groups of users or even for individuals whose personal interest profiles have been stored in the computer (selective dissemination of information).

It will probably be a long time, however, before this ultimate state of Utopia is reached and, in the meantime, reviews are likely to play an increasingly important part in the dissemination of information, providing scientists with a convenient short-cut to the primary literature, the searching for, and co-ordination of, related items of information having been carried out for them by someone else, preferably in a critical fashion by a specialist in the particular field.

\section{The sterility of modern science}

\section{By K. Mellanby, Monks Wood Experimental Station, Abbots Ripton, Huntingdon}

The 'information' explosion has been greatly overestimated. Data regarding the rate of increase of genuine research publications in various fields will be given, showing an absolute falling off in some subjects in recent years. There is sometimes a spurious increase caused by a flood of 'bogus' publications, often following international conferences, where the same itinerant speakers give the same lectures time after time. The most striking thing about modern science is that as it gets more expensive, and as more people are paid from the scientific budget, so it gets less efficient. 'Those who were selected as professors and as heads of departments as a result of their fruitful research records are - with a few notable exceptions to prove the rule-today almost completely sterile. These scientists are so busy planning future developments, that may never take place, that their subjects suffer. A rising proportion of research funds is being spent on things which hinder, rather than help, its progress. A drastic reorganization of science, with the elimination of many of the parasitic administrators and advisers who not only do not contribute to new knowledge, but who waste the time and energy of the remaining workers at the bench, is essential. 